\title{
Retaining our right to regulate alcohol warnings
}

\section{The Trans-Pacific Partnership Agreement must preserve Australia's options}

\section{(1)}

he Australian Government is engaged in negotiations for a Trans-Pacific Partnership Agreement (TPP) that may create barriers to Australia introducing the optimal health warnings scheme for wine and spirit containers.

Since 2010, Pacific-rim countries have been negotiating the terms of the TPP. There are now 12 parties: Australia, Brunei, Canada, Chile, Japan, Malaysia, Mexico, New Zealand, Peru, Singapore, the United States and Vietnam. It recently became known that a special annex on wine and spirits is being considered. The draft TPP text is confidential, and government officials have only revealed the general direction of negotiations to health stakeholders.

One purpose of the wine and spirits annex appears to be to simplify and standardise labelling requirements. It seems that the annex allows countries to prescribe labelling information, such as health warnings. However, the annex might limit what countries are able to do with the design and placement of such warnings. For example, it might allow placement of warnings on supplementary labels, rather than enabling governments to mandate that warnings be placed on principal labels.

It would be a blow to public health if Australia signed an agreement that made it difficult to create a fully effective alcohol warnings scheme for wine and spirits. Australia has major health and social problems associated with alcohol. ${ }^{1}$ Alcohol warning labels are one of the strategies that the World Health Organization has promoted to address alcohol-related harm. Recommendations about mandating alcohol warnings have also been made to the Australian Government as a result of recent government and parliamentary inquiries, including the National Preventative Health Taskforce.

The Australian Government appears to have left open the option of mandating alcohol warnings. In December 2011, it indicated that it was taking advice from the Standing Council on Health about introducing generic health warnings on alcoholic beverages (eg, "alcohol can damage your health"). If the advice has been given, it has not been made public, but the government has also not formally rejected this labelling option. At the same time, the government decided that "industry should be allowed a period of two years to adopt voluntary initiatives [for warnings about drinking during pregnancy] before regulating for this change ${ }^{\prime \prime}{ }^{2}$ An evaluation of industry labelling efforts is due to be completed by March 2014. Given these ongoing domestic policy processes, it is important that Australia conducts

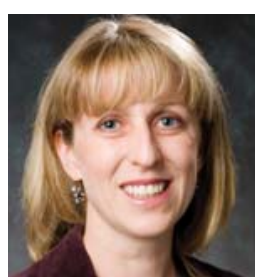

Paula L O'Brien BA/LLB(Hons), LLM, Senior Lecturer ${ }^{\dagger}$

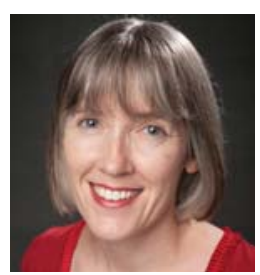

Deborah H Gleeson $\mathrm{BHSc}, \mathrm{MPH}, \mathrm{PhD}$, Lecturer $^{2}$

1 Melbourne Law School, Melbourne, VIC.

2 School of Public Health

La Trobe University, Melbourne, VIC.

obrienpl@

doi: 10.5694/mjal3.11006 University of Melbourne, and Human Biosciences, unimelb.edu.au

its TPP negotiations in a way that preserves its capacity to regulate warning labels once the results of the industry evaluation are known.

In particular, Australia needs to ensure that it can implement a scheme that reflects the best available evidence on the effectiveness of alcohol warnings. Results from a study of US alcohol warning labels suggest that warnings have effects on knowledge, attitudes and intervening variables, such as intention to change drinking habits. ${ }^{3}$ It has also been argued that the effectiveness of alcohol warnings may be increased by using the approach to tobacco warnings. Under this model, alcohol warnings would be positioned prominently on the front of the container (horizontal in orientation), consist of text and graphics, have a standard design, cover a designated proportion of the label and be rotated regularly. ${ }^{3,4}$

If these are the basic requirements for alcohol warning labels to be effective, the TPP must not prevent countries from implementing well designed and optimally placed warning labels. If Australia's options for the design and placement of warning labels are limited, the industry could place warnings in obscure locations on containers. Research conducted in June 2012 found that 12 months after the industry's voluntary DrinkWise Australia labelling scheme had started, only one alcoholic product out of a sample of 250 contained a health message on the front of the product. ${ }^{5}$

In the push to finalise the TPP by the end of 2013, Australia must ensure that the text does not restrict its capacity to design the best possible warnings scheme for wine and spirits. If there is a risk that the annex may introduce such restrictions, the annex must contain a strongly worded public health exception and Australia must be prepared to use the exception to tackle its problems with alcohol. Despite pressure from the alcohol industry, Australia must lead the way with alcohol health warnings, as it has with plain packaging of tobacco.

Competing interests: Paula O'Brien is a member of the Public Health Association of Australia. Deborah Gleeson receives funding from the Australian Research Council, is a member of the Public Health Association of Australia, and is active in the People's Health Movement.

Online first 2/10/13 Provenance: Not commissioned; externally peer reviewed.

1 Begg S, Vos T, Barker B, et al. The burden of disease and injury in Australia 2003. Canberra: Australian Institute of Health and Welfare, 2007. (AIHW Cat. No. PHE 82.)

2 Legislative and Governance Forum on Food Regulation (convening as the Australia and New Zealand Food Regulation Ministerial Council). Response to the recommendations of Labelling Logic: Review of Food Labelling Law and Policy (2011). Canberra: FoFR, 2011.

3 Wilkinson C, Room R. Warnings on alcohol containers and advertisements: international experience and evidence on effects. Drug Alcohol Rev 2009; 28: 426-435.

4 AER Foundation. Alcohol product labelling: health warning labels and consumer information. Canberra: AER Foundation, 2011.

5 Ipsos Social Research Institute. Alcohol label audit: prepared for the Foundation for Alcohol Research and Education. Sydney: ISRI, 2012. 